\title{
Tolerance analysis in manufacturing using process capability ratio with measurement
} uncertainty

\author{
Mahshid, Rasoul; Mansourvar, Zahra; Hansen, Hans Nørgaard
}

Published in:

Precision Engineering

Link to article, DOI:

10.1016/j.precisioneng.2017.12.008

Publication date:

2018

Document Version

Peer reviewed version

Link back to DTU Orbit

Citation (APA):

Mahshid, R., Mansourvar, Z., \& Hansen, H. N. (2018). Tolerance analysis in manufacturing using process capability ratio with measurement uncertainty. Precision Engineering, 52, 201-210.

https://doi.org/10.1016/j.precisioneng.2017.12.008

\section{General rights}

Copyright and moral rights for the publications made accessible in the public portal are retained by the authors and/or other copyright owners and it is a condition of accessing publications that users recognise and abide by the legal requirements associated with these rights.

- Users may download and print one copy of any publication from the public portal for the purpose of private study or research.

- You may not further distribute the material or use it for any profit-making activity or commercial gain

- You may freely distribute the URL identifying the publication in the public portal 


\section{Accepted Manuscript}

Title: Tolerance analysis in manufacturing using process capability ratio with measurement uncertainty

Authors: Rasoul Mahshid, Zahra Mansourvar, Hans Nørgaard Hansen

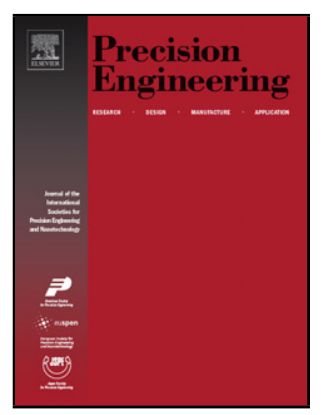

PII:

S0141-6359(17)30512-3

DOI: https://doi.org/10.1016/j.precisioneng.2017.12.008

Reference: PRE 6707

To appear in: Precision Engineering

Received date: 22-8-2017

Revised date: 26-11-2017

Accepted date: $15-12-2017$

Please cite this article as: Mahshid Rasoul, Mansourvar Zahra, Hansen Hans Nørgaard.Tolerance analysis in manufacturing using process capability ratio with measurement uncertainty.Precision Engineering https://doi.org/10.1016/j.precisioneng.2017.12.008

This is a PDF file of an unedited manuscript that has been accepted for publication. As a service to our customers we are providing this early version of the manuscript. The manuscript will undergo copyediting, typesetting, and review of the resulting proof before it is published in its final form. Please note that during the production process errors may be discovered which could affect the content, and all legal disclaimers that apply to the journal pertain. 


\title{
Tolerance analysis in manufacturing using process capability ratio with measurement uncertainty
}

\author{
Rasoul Mahshid ${ }^{\mathrm{a}, *}, Z^{*}$ ahra Mansourvar ${ }^{\mathrm{b}}$, Hans Nørgaard Hansen ${ }^{\mathrm{a}}$ \\ ${ }^{a}$ Department of Mechanical Engineering, Technical University of Denmark, Lyngby, Denmark \\ ${ }^{b}$ Department of Statistics, University of Isfahan, Isfahan 81744, Iran \\ *amah@mek.dtu.dk (corresponding author)
}

\section{Highlights}

- A statistical analysis for achievable tolerances in manufacturing is proposed.

- The analysis used process capability ratio and measurement uncertainty.

- The tolerances obtained from the proposed analysis showed good agreement compared to other statistical methods such as root-sum-square (RSS) in the case study.

- Combined expanded uncertainty should be controlled to improve and lower the limits in achieved tolerances.

\begin{abstract}
Tolerance analysis provides valuable information regarding performance of manufacturing process. It allows determining the maximum possible variation of a quality feature in production. Previous researches have focused on application of tolerance analysis to the design of mechanical assemblies. In this paper, a new statistical analysis was applied to manufactured products to assess achieved tolerances when the process is known while using capability ratio and expanded uncertainty. The analysis has benefits for process planning, determining actual precision limits, process optimization, troubleshoot malfunctioning existing part. The capability measure is based on a number of measurements performed on part's quality variable. Since the ratio relies
\end{abstract}


on measurements, elimination of any possible error has notable negative impact on results. Therefore, measurement uncertainty was used in combination with process capability ratio to determine conformity and nonconformity to requirements for quality characteristic of a population of workpieces. A case study of sheared billets was described where proposed technique was implemented. The use of ratio was addressed to draw conclusions about non-conforming billet's weight expressed in parts per million (ppm) associated with measurement uncertainty and tolerance limits. The results showed significant reduction of conformance zone due to the measurement uncertainty. Keywords: quality control; tolerance; expanded uncertainty; capability ratio; statistical analysis; manufacturing; sheared billet; cold forming

\section{Introduction}

Each manufacturing operation creates a feature that is subjected to variations. If manufacturing technology for a part is known, there is a limit to the minimum achievable variation that the quality feature under consideration cannot become better than that level. The limits vary from one manufacturing process to another, and is inherently difficult to predict them. For a particular manufacturing method, it is primarily controlled with intervention of machine operator during production stage. The operator changes parameters (input variables) on machine tool and by quality characteristic's inspection, the optimum values are found. Therefore, process performance is left to operator experience. Depending on the complexity of the process, this traditional way of optimization can be time consuming and costly to manufacturers. In order to address this problem, optimization techniques have been developed to balance a trade-off between machine workability, production time, surface quality and dimensional accuracy. Several experimental designs and optimization methods such as Taguchi, full factorial, gray relational, fractional factorial, artificial neural network 
(ANN), fuzzy logic and genetic algorithm (GA) were introduced for optimizing operating parameters in manufacturing processes. The procedure is also highly dependent on identification of the critical parameters and functional relationship between the parameters and part quality characteristics. For some manufacturing methods such as metal-based additive manufacturing where material undergoes complicated physical deformation, it is difficult to find critical-to-quality process variables and relate them to part quality [1].

Although the knowledge of process, operator skills and the optimization techniques are effective, there should be a method for the above-mentioned improving efforts in order to provide lower bounds on process yields with respect to allocated tolerances at engineering drawings. Therefore, if a tolerance analysis can be developed to measure the actual process performance (achievable tolerances) for manufacturing precision products, there is a potential to improve systematically process efficiency by decreasing development efforts and productions costs.

Since quality improvement attempts deal with variability and the only way to describe this, is in statistical terms, statistical methods have central role in tolerance analysis. Every aspect of manufacturing business is significantly influenced by the limits in engineering design as well as production level. Tolerance analysis of manufactured parts checks the conformity of process to specified values, or to assist in modifying the process until the desired values are obtained (Fig. 1).

Beginning in the late 1980, researchers began investigating methods for selecting tolerances at design level (tolerance requirements as seen in Fig. 1). As this research has progressed, it has been found that design and manufacturing are the most important issues for mechanical tolerance analysis in order to ensure competitive products. In 1988, Chase and Greenwood [2] published a document regarding common and 
advanced tolerance analysis for designers. They demonstrated that quality control techniques must be used to determine process capability in order to make advanced tolerance analysis and optimization methods available. In 1991, Kenneth et al. [3] reviewed applications of tolerance analysis for predicting the manufacturing effects on performance and quality control. It was discussed that Monte Carlo Simulation is capable for tolerance analysis of mechanical assemblies, for both nonlinear assembly functions and non-Normal distributions. Moreover, Nigam and Turner [4] discovered that the role of tolerance requirements is to indicate a choice of manufacturing technology and process parameters. Then it is statistical tolerance analysis that has to determine the effect of manufacturing process on the part precision, and associated specification limits has no more relevance at this stage. From studies conducted by Gerth and Hancock [5], the effectiveness of Monte Carlo Simulation was validated with actual production data to improve a complex process system that contains large number of variables. It was also shown that Monte Carlo and Root-sum-square (RSS) are the most common and reliable statistical methods available for tolerance analysis. In 2011, Fischer [6] published a document and discussed, that when assuming all component tolerances to be $\pm 1 \sigma, \pm 2 \sigma, \pm 3 \sigma$, then the RSS assembly tolerance represents $\pm 1 \sigma, \pm 2 \sigma, \pm 3 \sigma$ respectively.

Due to the simplicity and effectiveness, process capability ratios $\left(C_{p}\right.$ and $\left.C_{p k}\right)$ have been used to represent the ability of the process to manufacture products that consistently stays within the specification limits [7]. These numerical measures may quantify process potential and performance using suitable statistical methods. The ratios have received substantial attentions in engineering literature as well. Wu et al. [8] published a review of theory and practice on process capability ratios for quality assurance for years 2002 to 2008 at which applications of these ratios over a variety of processes and 
productions are discussed. Statistical tools are often used for tolerance analysis in manufacturing. In 2012, Barkallah et al. [9] developed a statistical method for simulation of 3D manufacturing tolerances of a milling process using small displacement torsors (SDT). In 2013, the quality control of injection-molded micro mechanical parts was explored using uncertainty measurement, quality control approach and measuring instrument capability ratios by Gasparin et al. [10]. Khodaygan and Movahhedy [11] used the concept of process capability to propose new functional process capability ratios for estimation of process performance expressed in nonconforming percentage and performed sensitivity analysis for optimization of process variables. Additionally, Singh [12] conducted a study for process capability analysis of fused deposition modelling (FDM). The results realized $\pm 4.5 \sigma$ limit for dimensional accuracy of plastic component used in bio-medical applications. Recently, Kumar et al. [13] concluded that three dimensional printing as casting solution for nonferrous alloys is capable ( $C_{p} \geq 1.33$ ) of manufacturing components within $\pm 5 \sigma$ limit with respect to dimensional accuracy. However, the effect of gauge measurement errors were not considered in capability calculations in the last two studies.

The aim of this study is to develop a simple tolerance analysis based on conventional process capability ratio. In particular, the analysis describes tolerances, which can be achieved when manufacturing technology is known. The paper will examine if reliable control limits can be established to adjust expectations for future production. The data for statistical analysis are from measurements performed on actual workpieces. Consequently, the sample data are affected by errors caused by measuring instrument, environment and workpieces. In this paper, the measurement uncertainty will be used and compared to tolerances calculated from process capability ratio to obtain reliable critical limits and confidence bounds. The conformity with a calculated tolerance will 
be proved when the complete measurement result (measurements including measurement uncertainty) falls within conformance zone of a workpiece characteristic according to ISO standard. The proposed method has several benefits for process decision-making and process optimization. There is no need to define functional relationships between quality characteristics and critical-to-quality variables. This paper provides a case study illustrating the achievements of the proposed method. The materials and tools used in the case study for sample production are presented in Section 2. In section 3, the methodology and the basic concepts for both process capability ratio and measurement uncertainty along with their limits and requirements, are discussed. Section 4 explains results for conformity testing to use of process capability ratio. In addition, the calculations of measurement uncertainty for quality variables under consideration are obtained. In Section 5, tolerance analysis is described. The limits from the proposed method are validated with the tolerances obtained from worst case and RSS methods. A full description of tolerances with respect to measurement uncertainties for the case study are discussed.

\section{Material and tools}

For many years, shearing has demonstrated prominent cutting method, which is characterized by high speed and low material loss. The method has also received attention for high performance in various applications such as biomedical [14], optical MEMS [15], electrical motors [16], lithium-ion cell stacking [17] and billet shearing [18].

For precision manufacturing of micro metal parts in a micro cold former, it is important to maintain tight dimensional tolerances on cropped billets (Fig. 2) in order to control the volume of material at each forming operation; otherwise, the force distribution (F1 
and F2 in Fig. 2) is impaired on the upper plate of former. Consequently, this will cause tool deflection, which introduces errors in geometry of final produced parts. To reduce this variability, a tolerance of $0.5-1 \%$ is generally recommended for weight of billets in solid forming [19].

A cropping tool with bar and cutoff holder was manufactured. The shearing tool primarily was developed to fabricate billets for precision manufacturing of micro metal parts using high performance transfer press [20,21]. The testing material is Aluminum with conditions illustrated in Fig. 3.

The wire has a nominal diameter of $2.0 \mathrm{~mm}$ according to the manufacturer's certificate, thereby expecting IT12 $(\leq 0.1 \mathrm{~mm})$ tolerance on the diameter according to ISO $286-1$ [22]. Due to the proposed geometry of the final part the billets have nominal dimensions of $5.0 \mathrm{~mm}$ length and $2.0 \mathrm{~mm}$ diameter [21]. The cropping tool has fixed dimensions, since the dimensions of billets are the same throughout the experiments. In order to evaluate efficiency of the cropping device to be functional, a tolerance of $\pm 0.212 \mathrm{mg}$ $(0.5 \%)$ for the weight is required (Aluminum's density: $2.7 \mathrm{mg} / \mathrm{mm} 3$ ) according to the general recommendations previously mentioned. Critical-to-quality process variables are diameter and length. When shearing stock material for billet production, the variability of diameter and length influence weight of billets. Therefore, tolerance analysis of diameter and length was necessary to evaluate corresponding tolerances on the weight as it is illustrated in Fig. 4.

A volume production of 1250 billets by means of the cropping tool was employed. The production was performed in 25 consecutive groups of 50 billets each. Fig. 5 shows 
representatives of produced billets and the manufacturing operations by the prototype device.

The measuring procedure consisted of selection six specimens of each batch randomly for length and weight measurements. To verify repeatability and guard against operator error, any measurements were made at five tries for each sample [23]. The analysis used the average of repeated measurements. Therefore, twenty-five-sample's groups, each of size six, have been taken for analysis. In total, the analysis has 150 observations in order to estimate process capability ratio.

A SHIMADZU AW220 analytical balance was used for weight measurements. The instrument has $0.1 \mathrm{mg}$ resolution and $0.1 \mathrm{mg}$ standard deviation. A micrometer measured the length of billets. It has one $\mu \mathrm{m}$ resolution and a digital display. The measurements are performed in a controlled temperature room. Since volume and weight are proportional, it is obvious that weight measurements also depict the variability of the volume.

\section{Method}

Traditionally, process capability is used to determine whether or not a manufacturing process is capable to produce parts within predetermined level of tolerance. A quantitative way to express process capability is in terms of process capability ratio $\left(C_{p}\right)$ which for quality characteristics with both upper and lower specification limits (USL and LSL, respectively) is

$$
C_{p}=\frac{\mathrm{USL}-\mathrm{LSL}}{6 \sigma}
$$

where $\sigma$ is standard deviation. For the analysis described in this research, it was assumed that the process is centered at the midpoint of the specifications $\left(C_{p}=C_{p k}\right)$. The ratio predicts how well the process hold the tolerances. It is common to calculate 
process capability numerator based on collected data and specification limits, which are already assigned in engineering design. Among the major benefits of process capability ratio is the use of ratio to draw conclusion about process performance with the associated values of process fallout, expressed in defective parts or nonconforming units of product per million (ppm).

The aim of this research is to develop a new method for tolerance analysis at manufacturing level (Fig. 1). It must be noted that the tolerance analysis discussed in this paper is not the same as those obtained at engineering design. These are achievable tolerances when manufacturing method and process parameters are known. However, tolerances at engineering design are the requirements that the final product must reach them in order to assure its proper functionality in a mechanical assembly. Process capability ratio, which is a long established measure for actual process performance analysis, is of interest in this research for tolerance evaluation. Typically, process capability ratio is assessed when specification limits (from engineering design) and standard deviation are known. For this research, however, the tolerance is calculated when process capability and standard deviations are present (using eq. 1). To avoid serious error in reported quantities, special care should be exercised using process capability ratio and ppm quantities. They require assumptions of (1) the individual data is independent (2) the process is in control (3) the distribution of process quality characteristics is normal, that need to be checked. Somerville and Montgomery [24] reported the effect of the normality assumption on the ppm nonconforming level for four non-normal distributions. They showed that the assumptions are absolutely critical and small deviation form normality have significant impact on the error associated with process capability ratios to estimate ppm quantities. 
Measurements are big part of process capability calculations. An ineffective measurement system significantly leads to bad decision-making base. Any activity involving measurements includes errors and uncertainties, which may come from measuring instrument, measurands, measurement process, operator's skill, sampling and environment. The measurement errors also decrease the performance of control charts in process monitoring applications. Therefore, taking into account the effect of measurement error in tolerance analysis is inevitable.

Recently, Maleki M. R. [25] published a literature review presenting the methods researchers have investigated, for the effect of measurement errors on statistical process monitoring using process capability analysis. In 2002, Bordignon and Scagliarini [26] showed a statistical analysis on process capability ratio $\left(C_{p}\right)$ for measurements contaminated with errors using additive error model and a single quality characteristics. However, there was a need for a method that investigates the error model with several correlated quality characteristics and gauge measurement error. In 2011, Scagliarini [27] reported on the effect that gauge measurement error had on multivariate process capability ratios.

It is important to notice that measurement error is the difference between the true quantity value and the measured value. For any error whose value is known, the corrections are applied to the system. However, the errors are not observable and generally unknown and give contributions to the uncertainty of the measured value. Any error whether or not its value is known, is a source of uncertainty causing dispersion around the mean value of the measurand. Uncertainty of measurement describes the quality and the existing doubts of measurements used for process capability estimator. For this research, measurement uncertainty presents the effect of measurement error on the specification limits calculated from process capability ratio. ISO 22514-7:2012 (E) 
[28] establishes a statistical method to calculate capability ratio for measurement processes based on combined standard uncertainty. The formulas are based on engineering tolerances as reference. The standard also defines the relation between observed process capability and measurement capability ratio. ISO 26303-2012 [29] also discusses the influences due to measuring uncertainty that lowers the short-term capability ratios. ISO 26303-2012 defines standard deviation of the measuring device as measuring uncertainty. Moreover, the standard presents the requirement on the measurement equipment standard deviation $s_{g}$ as $6 s_{g} \leq 0.15 T, T$ is the tolerance of the feature under test. This means that the minimum measurable tolerance is $80 \mu \mathrm{m}$ for a measuring device with $1 \mu \mathrm{m}$ standard deviation and capability ratio of 2 .

In this research, the methodology is based on the relation between tolerances and observed process capability ratio (eq. 1), as well as the relation between tolerances and measurement uncertainties. The relationship between calculated tolerances and the estimated combined uncertainty relies on ISO 14253-1 [30]. The standard takes into account the estimated measurement uncertainty to prove conformity, nonconformity and uncertainty range with respect to a given tolerances. Fig. 6 illustrates how measurement uncertainty lowers the bandwidth for conformity and nonconformity zones with respect to specification limits. When viewing the figure, it also becomes apparent that the tolerance must be greater than the measurement uncertainty in order to make conformity zone available. Therefore, each specification limits calculated from process capability ratio must be followed by associated measurement uncertainty; otherwise, the results are contaminated with errors and lead to poor process planning.

\section{Results}

The aim of this paper was to analyze achievable tolerances in manufacturing by means of process capability numerator. This was to draw conclusions about the process 
performance expressed in parts per million (ppm) nonconforming. The analysis required important assumptions: normal distribution, process statistically in control and independent parameters. In combination with tolerance analysis, calculation of measurements uncertainty was necessary to determine availability of conforming zone. In this section, first the assumptions is validated for the case of sheared billets. Second, measurement uncertainty is calculated along with the mean and standard deviation for each variable in the case study.

\subsection{Assumptions validity}

The individual measurements are independent. A particular observation for weight and length had no dependency on a previous observation when each measurement was performed on a separate workpiece. 150 observations available for analysis provided enough stability for the histogram to obtain reasonably reliable estimate of process normality. The histogram had the advantage to give an immediate, visual impression of process distribution using sample average and sample standard deviation. Probability plot was also used to determine the shape, center, and spread of the distribution. The plots were supplemented with the Ryan-Joiner (Shapiro-Wilk) test for normality. The Shapiro-Wilk test is highly recommended for normality test when analyzing data from a manufacturing process [31]. The Ryan-Joiner (RJ) test for normality is similar to the Shapiro-Wilk and it is simpler to implement in a software [32]. The test is implemented in the Minitab software package which was used for statistical analysis in this paper. The histograms and probability plots for both datasets are shown in Fig. 7. The information listed in Fig. 7 (c) and (d) showed RJ $\approx 1$ and P-valued $>0.1$ with RyanJoiner test which meant the datasets are normal. While not shown, Anderson-Darling and Kolmogorov-Smirnov tests were applied and they confirmed the normally distributed of data as well. 
A process is statistically in control if both mean value of quality characteristic and its variability are in control. Control charts are effective tools for this purpose. They have been used for process monitoring, analysis and control steps in Define, Measure, Analyze, Improve, and Control (DMAIC) problem solving process. The normality and independence of data are fundamental for assessing the performance and suitability of control charts. Control of process average is performed using $\bar{x}$ control chart. For process variability, control chart for the range, called an $\mathrm{R}$ control chart is more widely used. The range of sample is the difference between the maximum and minimum observations for a sample of size $\mathrm{n}$. Both control charts for length and weight shown in Fig. 8, were constructed by Minitab. From visual inspection of the charts, no indication of out-of-control conditions was observed on R charts. However, failure tests occurred in $\bar{x}$ chart for length (two points) and weight (3 points). When a chart is out-of-control, the procedure is to eliminate out-of-control points and recompute a revised value $\bar{x}$. While eliminating out-of-control points from data, slight changes were found to exist in sample average for length $(0.0001 \mathrm{~mm})$ and weight $(0.02 \mathrm{mg})$. This variability was deemed negligible for the purpose of this paper. Since both the $\bar{x}$ and $\mathrm{R}$ charts exhibited control, we concluded that the process is in control at the stated levels.

\subsection{Uncertainty of measurements}

To establish uncertainty calculations, it is important that the parts are being manufactured in a normally distributed process. In this paper, the uncertainty calculation was conducted based on GUM (Guide to the expression of Uncertainty in Measurement) [33] and ISO 14253-2 [34] which characterize the quantity by a Gaussian (or normal) distribution. A good point about ISO 14253-2 is that the document includes a list of sources, common for uncertainty of dimensional measurements. It is also useful for cases where uncertainty of quality characteristic (such as weight) is calculated 
directly from the same measurement system. The strength of GUM is that it provides a method to calculate uncertainty of a measurand, which has a functional relationship with measurements of input variables through combining uncertainty components of the variables. This method used for measurement uncertainty of diameter of billets. The symbols that were used in this paper for uncertainty calculation are provided in Table 1. The tables of uncertainty calculations used notations and terms provided by GUM. The following definitions are those used in the tables for uncertainty calculation in this paper:

- Standard uncertainty: standard deviation of quality characteristic obtained from measurements expressed as uncertainty of the result.

- Type A evaluation (of uncertainty): Any method using statistical analysis of measurements for uncertainty evaluation.

- Type B evaluation (of uncertainty): Any method for uncertainty estimation from any other information rather than statistics.

- Combined standard uncertainty $\left(u_{c}(y)\right)$ : standard uncertainty of the result of a measurement when that result is obtained from the values of a number of other quantities, equal to the positive square root of a sum of terms, the terms being the variances or covariances of these other quantities weighted according to how the measurement result varies with changes in these quantities. Combined standard uncertainty may contain terms whose components are derived from Type A and/or Type B evaluations without discrimination between types.

- Expanded uncertainty $(U)$ : A measure of uncertainty that defines an interval about the result of measurement that is expected to include a large fraction of the distribution of values that could reasonably be attributed to the measurand $\mathrm{y}$. 
- Coverage factor $(k)$ : numerical factor used as a multiplier of the combined standard uncertainty in order to obtain an expanded uncertainty $\left(U=k u_{c}\right)$.

Therefore, it is confidently believed that the true value of the measurand $y$ is written as,

$Y=y \pm U$

The GUM introduced degree of freedom against small numbers of repeated measurements. It asks evaluation of the coverage factor $(k)$ which is chosen to be $t_{\alpha, v}$ critical value from $t$-table with $v$ degree of freedom. For large numbers of repeated measurements, $k=2$ approximates $95 \%$ confidence level. The degree of freedom associated with combined standard uncertainty $u_{c}$ is approximated by the WelchSatterthwaite formula (the last column in the uncertainty tables).

The tables also have coverage factors $k_{a i}$ for Type A and $k_{b i}$ for Type B. When importing expanded uncertainty from a previous calibration in tables for Type A, standard uncertainty is obtained using coverage factor $k_{a i}=2$. For Type B estimates, when the upper and lower limits of uncertainty are available, while additional information for distribution is scarce, standard uncertainty for a rectangular distribution is obtained from $a / \sqrt{3}$ and therefore $k_{b i}=3$ was used in the tables.

In the case of direct measurement of variable $x_{i}$ estimated by the mean of $N$ independent observation, systematic error of measuring instrument (bias), resolution of measuring instrument and repeatability of measurements contribute in uncertainty calculations. The degree of freedom for repeatability of $N$ observations is equal to $N-1$. Degree of freedom $v$ for Type B uncertainties based on rectangular distribution, according to the convention in GUM, is assumed to be infinitive. 


\subsection{Uncertainty calculation for length and weight}

The measuring instrument for length is a regular micrometer that came with no calibration certificate. To establish traceability of the micrometer, the micrometer was calibrated using standard gauge blocks, which served as the "master". The master is a 5 mm grade 2 gauge block [35]. The calibration certificate for the gauge block indicates expanded uncertainty $0.18 \mu \mathrm{m}$ on the length for the master. 30 measurements were repeated using the micrometre for the gauge block, with mean $5.0017 \mathrm{~mm}$ and standard deviation $1.7 \mu \mathrm{m}$. The variables $\left(x_{i}\right)$ were uncertainty of measuring instrument (bias), repeatability, resolution of measuring instrument, uncertainty of thermometer, uncertainty of coefficient of thermal expansion and uncertainty due to temperature differential between micrometer and standard. Expanded uncertainty $0.0037 \mathrm{~mm}$ was obtained for calibration of the micrometer (Table 2).

When applying the uncertainty of measuring instrument associated with Table 2, while using the repeatability of measurements from Fig. 7 for billet's length, Table 3 computed expanded uncertainty for the length that was found to be $0.008 \mathrm{~mm}$. The information from the balance manufacturer (SHIMADZU AW220 Analytical Balance) indicated standard uncertainty and resolution $0.1 \mathrm{mg}$. Table 4 lists the variables contributed in measurement uncertainty of weight and the expanded uncertainty $0.39 \mathrm{mg}$ was found.

\subsection{Uncertainty calculation for diameter}

Diameter is another quality characteristic for sheared billets and has notable effect on the weight variability. The tolerance analysis of this parameter indicates the desirable diameter quality for the stock material, which comes from external suppliers (Fig. 3). To determine the effect of diameter on the weight of billets, it is important to get insight into statistics of this variable; mean, standard deviation and expanded uncertainty (In 
case of direct measurement, the statistics for diameter are calculated from the measurements at some points on the billet's length using a measuring instrument such as micrometer). From density's definition, the functional relationship for diameter is

$$
D=\sqrt{(4 m) /(\pi \rho h)}
$$

Where $m, h, \rho$ are mass, length and density respectively. When using density 2.7 $\mathrm{mg} / \mathrm{mm}^{3}$ and average for mass $\left(\mu_{m}=41.65 \mathrm{mg}\right)$ and length $\left(\mu_{h}=5.050 \mathrm{~mm}\right)$, mean $1.9709 \mathrm{~mm}$ was calculated for diameter. While not performing any measurements on diameter of billets, diameter variance was approximated using Taylor expansions of $D=f(m, h)$ in order to calculate the standard deviation of diameter [36].

Using the first order Taylor expansion for $D=f(m, h)$ expanded around $\theta=f\left(\mu_{m}, \mu_{h}\right)$

$$
\operatorname{Var}(f(m, h)) \approx f_{m}^{\prime 2}(\theta) \operatorname{Var}(m)+2 f_{m}^{\prime}(\theta) f_{h}^{\prime}(\theta) \operatorname{Cov}(m, h)+f_{h}^{\prime 2}(\theta) \operatorname{Var}(h)
$$

When returning to $D=f(m, h)$, while $\operatorname{Cov}(m, h)=0$ (independent parameters),

$$
\operatorname{Var}(D)=\frac{1}{\pi \rho}\left[\frac{\sigma^{2}{ }_{m}}{\mu_{m} \mu_{h}}+\frac{\mu_{m} \sigma_{h}^{2}}{\mu_{h}{ }^{3}}\right]
$$

where $\sigma_{m}$ and $\sigma_{h}$ are standard deviations for mass and length respectively. Once again, when using the values shown in Fig. 7, standard deviation $0.0042 \mathrm{~mm}$ was found for diameter. Given the functional relationship for measurand $D$ in terms of uncorrelated input quantities $m$ and $h$ (eq. 3 ), the combined standard uncertainty $u_{c}(D)$ was obtained by combining the standard uncertainties of the input estimates as outlined in the GUM.

$$
u_{c}^{2}(D)=\left[\frac{\partial D}{\partial m} u(m)\right]^{2}+\left[\frac{\partial D}{\partial h} u(h)\right]^{2}
$$


The calculation was illustrated in Table 5 and expanded uncertainty $0.0093 \mathrm{~mm}$ was found for diameter.

In summary, the datasets included 150 independent observations for weight and length of sheared billets. The assumption of normal distribution was proved to be true for both measurements. $\bar{x}$ and $\mathrm{R}$ control charts showed that the process was in control. The statistics of quality variables obtained in this section are listed in Table 6.

\section{Discussion}

The process capability ratio can be used before the start of serial production as a measure of process performance to indicate the ability of the process to manufacture a product within tolerance requirements. As mentioned in Section 3, it is common to calculate process capability ratio when tolerance requirements are available. In this paper, however, specification limits are calculated from process capability ratio. Process capability ratio $\left(C_{p}\right)$ and associated process fallout (two-sided specification) expressed in defective parts or nonconforming units of product per million (ppm) for a normally distributed process that is in statistical control are listed in Table 7 and Table 8 . When assuming tolerance being proportional to standard deviation $($ Tolerance $= \pm k \sigma)$, corresponding process capability ratio and tolerances are shown in the tables. Table 7 and Table 8 also present the equivalent tolerances obtained for length and diameter along with conformance zone available for each variable using uncertainty-to-tolerance ratio.

Recommended minimum values of process capability ratio are 1.33 (for existing processes) and 1.5 (for new processes) for a two-sided specifications [37]. The corresponding tolerance values for process capability ratio 1.33 and 1.5 were $\pm 4 \sigma$ and $\pm 4.5 \sigma$ respectively as can be seen in Table 7 and Table 8 . When comparing the tolerance values to the uncertainty-to-tolerance $(U / T)$ ratio, however, significant 
reduction of the available conformance zone was observed for the recommended values. The rules of metrology recommend the uncertainty-to-tolerance ratio to be between 0.1 and 0.2 , then the measurement uncertainty has no effect on the tolerance [38].

The solutions for decreasing measurement uncertainty have been tried by improving the measuring system [39] and measuring method [40] and drastic reduction of uncertaintyto-tolerance were verified. In addition, it must be noted that the recommended process capability ratios are only minimums. Changing the criteria can increase the tolerance range causing decrease of uncertainty-to-tolerance ratio. For example, adopting Six Sigma model $\left(C_{p}=2\right)$ will increase the tolerance range to $\pm 6 \sigma$ and improves $U / T$ to 38\% (Table 7 and Table 8) which may be beneficial for the current process state. In the same manner, the tolerance was calculated for weight using process capability ratio. The tolerances are listed in Table 9 along with uncertainty-to-tolerance ratio for weight. Weight has a simple functional relationship with length and diameter in this case study. Therefore, the case study is a two-dimensional tolerance analysis, and weight tolerance can be computed using worst-case (WC) and root-sum-squared methods. While worst-case model determines the accumulated $\left(T_{\text {weight }}\right)$ tolerance by summing the component tolerances $\left(T_{i}\right)$ linearly (eq. 7 ), component tolerances are added as the root-sum-squared in RSS analysis (eq. 8). RSS model assumes distribution of the component variable to be normal.

$$
\begin{aligned}
& T_{\text {weight }}=\sum\left(\left|\partial f / \partial x_{i}\right| T_{i}\right) \\
& T_{\text {weight }}=\left[\sum\left(\partial f / \partial x_{i}\right)^{2} T_{i}^{2}\right]^{1 / 2}
\end{aligned}
$$

Where $x_{i}$ are the nominal component dimensions (length and diameter) and $f\left(x_{i}\right)$ is the weight function in terms of length and diameter. Weight tolerances were calculated 
using the two models and the results are listed in Table 9. When comparing the tolerances from process capability ratio to the tolerances from WC and RSS methods, a good agreement with RSS method was observed. One possible reason for this is that, both methods have origins in statistical behavior of the process.

A special emphasis in the case study of this paper is laid on the question, which arise for the minimum weight error, which is a critical-to-quality characteristic for billet manufacturing in solid cold forming. When increasing the tolerance range, more variability of length and diameter are allowed and the weight error becomes worse for sheared billets. The guidelines as a rule recommended $\pm 0.5 \%$ weight error for precision manufacturing of forged parts. The maximum weight errors associated with tolerances on the length and diameter are listed in Table 9. The maximum weight error $\pm 0.5 \%$ $(0.212 \mathrm{mg})$ was achieved at the tolerance range of \pm 1 standard deviation corresponding to process capability ratio 0.33 , in which no conformance zone was available with respect to the measurement uncertainty. This implies that neither appropriate process parameter, nor reasonable measurement uncertainty is feasible for the required weight error at the stated production condition.

\section{Conclusion}

A statistical tolerance analysis was presented for manufacturing processes using process capability ratio. In particular, the analysis was performed on workpieces at production stage when the manufacturing process is known. This was based on sample measurements. Therefore, measurement uncertainty was included to compensate for all possible errors due to experimental setup errors, time-varying parameters, tool wear, measuring method and measuring instrument. The uncertainty of measurements determined the conformance zone with respect to the tolerances obtained from statistical tolerance analysis. There was no need for functional relationships between the tolerance 
variables from geometry or theory. The effectiveness of proposed method was verified in the case study for the weight of sheared billets when comparing the tolerance limits calculated from process capability ratio to the limits obtained from RSS and worst-case methods. The method proved to be successful for actual process performance evaluation in quantifiable manner. The calculated tolerances showed benefits for process planning (as it was shown for billet production).

The method has also some limitations. First, the normality assumption is critical in which moderate and small deviation from normality have significant effect on the error associated with using $C_{p}$ to estimate the PPM. The same situation is for measurement uncertainty when GUM assumes that variables follow Gaussian distribution. Therefore, the recommendation is that a normal probability plot of the data accompanies calculation of conventional process capability ratio and uncertainty to verify adequacy of the normality assumption. Second, the methodology used the data from in-control process. The analysis required a "clean" set of data gathered under stable condition, which represents in-control process performance. Sometimes this type of analysis needs several cycles; the points outside the control limits are detected, revised control limits are calculated and the out-of-control action plan is updated.

The analysis described in this research relied on processes with normal distribution data. While this allowed to show the effectiveness of the method, enhancement would be expected for the proposed analysis, if tolerance calculation using capability ratio and measurement uncertainty were expanded to non-normal processes. 


\section{References}

[1] Tapia G, Elwany A. A review on process monitoring and control in metal-based additive manufacturing. J Manuf Sci Eng 2014;136:060801-10.

[2] Chase K, Greenwood W. Design issues in mechanical tolerance analysis. Manuf Rev 1988;1:50-9.

[3] Kenneth W, Chase K, Parkinson A. A survey of research in the application of tolerance analysis to the design of mechanical assemblies. Res Eng Des $1991 ; 3: 23-37$.

[4] Nigam S, Turner J. Review of statistical approaches to tolerance analysis. Comput Des 1995;27:6-15.

[5] Gerth R, Hancock W. Computer aided tolerance analysis for improved process control. Comput Ind Eng 2000;38:1-19.

[6] Fischer B. Statistical tolerance analysis. In: Fischer B, editor. Mech. Toler. stackup Anal. Second, Taylor \& Francis Group; 2011, p. 97-130.

[7] Kunzmann H, Pfeifer T, Schmitt R, Schwenke H. Productive metrology-adding value to manufacture. CIRP Ann Technol 2005;54:155-68.

[8] Wu C, Pearn W, Kotz S. An overview of theory and practice on process capability indices for quality assurance. Int J Prod Econ 2009;117:338-59.

[9] Barkallah M, Louati J, Haddar M. Evaluation of manufacturing tolerance using a statistical method and experimentation. Int J Simul 2012;11:5-16.

[10] Gasparin S, Tosello G, Hansen H, Islam A. Quality control and process capability assessment for injection-moulded micro mechanical parts. Int J Adv Manuf Technol 2013;66:1295-303. 
[11] Khodaygan S, Movahhedy M. Functional process capability analysis in mechanical systems. Int J Adv Manuf Technol 2014;73:899-912.

[12] Singh R. Process capability analysis of fused deposition modelling for plastic components. Rapid Prototyp J 2014;20:69-76.

[13] Kumar R, Singh R, Ahuja I. Process capability study of three dimensional printing as casting solution for non ferrous alloys. Rapid Prototyp J 2016;22:47486. doi:10.1108/RPJ-05-2014-0063.

[14] Petersen RS, Mahshid R, Andersen NK, Keller SS, Hansen HN, Boisen A. Hot embossing and mechanical punching of biodegradable microcontainers for oral drug delivery. Microelectron Eng 2015;133:104-9. doi:10.1016/j.mee.2014.11.009.

[15] Takeshita T, Iwasaki T, Higurashi E, Sawada R. Application of Nanoimprint Technology to Diffraction Grating Scale for Microrotary Encoder. Sensors Mater 2013;25:609-18.

[16] Kurosaki Y, Mogi H, Fujii H, Kubota T, Shiozaki M. Importance of punching and workability in non-oriented electrical steel sheets. J Magn Magn Mater 2008;320:2474-80. doi:10.1016/j.jmmm.2008.04.073.

[17] Baumeister M, Fleischer J. Integrated cut and place module for high productive manufacturing of lithium-ion cells. CIRP Ann - Manuf Technol 2014;63:5-8. doi:10.1016/j.cirp.2014.03.063.

[18] Mahshid R, Hansen HN. Precision analysis in billet preparation for micro bulk metal forming. Proc. 15th Int. Conf. Eur. Soc. Precis. Eng. Nanotechnology, EUSPEN 2015, euspen; 2015, p. 53-4.

[19] Kammerer M, Schöck J. Vorbehandlung. In: Lange K, Kammerer M, Pöhlandt K, Schöck J, editors. Fließpressen:, Springer; 2008, p. 81-117. 
[20] Mahshid R, Hansen HN, Arentoft M. Characterization of precision of a handling system in high performance transfer press for micro forming. CIRP Ann - Manuf Technol 2014;63:497-500. doi:10.1016/j.cirp.2014.03.001.

[21] Mahshid R, Hansen HN, Arentoft M. Towards Mass Production by High Performance Transfer Press in Micro Bulk Forming. Procedia Eng 2014;81:1445-50. doi:10.1016/j.proeng.2014.10.171.

[22] ISO 286-1:2010. Geometrical product specifications (GPS) -- ISO code system for tolerances on linear sizes -- Part 1: Basis of tolerances, deviations and fits 2010:38.

[23] Bell S. Measurement Good Practice Guide No. 11 (Issue 2). A Beginner's Guide to Uncertainty of Measurement. National Physical Laboratory: 2001.

[24] Somerville S, Montgomery D. Process capability indices and non-normal distributions. Qual Eng 1996;9:305-16.

[25] Maleki MR, Amiri A, Castagliola P. Measurement errors in statistical process monitoring: A literature review. Comput Ind Eng 2017;103:316-29. doi:https://doi.org/10.1016/j.cie.2016.10.026.

[26] Bordignon S, Scagliarini M. Statistical analysis of process capability indices with measurement errors. Qual Reliab Eng 2002;18:321-32.

[27] Scagliarini M. Multivariate process capability using principal component analysis in the presence of measurement errors. AStA Adv Stat Anal 2011;95:113-28. doi:10.1007/s10182-011-0156-3.

[28] ISO 22514-7:2012. Statistical methods in process management - Capability and performance - Part 7: Capability of measurement processes 2012.

[29] ISO 26303:2012. Machine Tools - Short-term capability evaluation of machining processes on metal-cutting machine tools 2012. 
[30] ISO 14253-1:2013. Geometrical product specifications (GPS) -- Inspection by measurement of workpieces and measuring equipment -- Part 1: Decision rules for proving conformity or nonconformity with specifications 2013.

[31] Ghasemi A, Zahediasl S. Normality tests for statistical analysis: a guide for nonstatisticians. Int J Endocrinol Metab 2012;10:486-9.

[32] Ryan T. Normal probability plots and tests for normality. Stat Dep Pennsylvania State Univ 1974.

[33] JCGM 100:2008. Guide to the Expression of Uncertainty in Measurement (GUM) 2008.

[34] ISO 14253-2:2011. Geometrical product specifications (GPS) -- Inspection by measurement of workpieces and measuring equipment -- Part 2: Guidance for the estimation of uncertainty in GPS measurement, in calibration of measuring equipment and in product verification 2011:71.

[35] ISO 3650:1998. Geometrical Product Specifications (GPS) -- Length standards -Gauge blocks 1998:1-15.

[36] Elandt-Johnson R, Johnson N. Survival models and data analysis. New York: John Wiley \& Sons; 1999.

[37] Montgomery D. Process and Measurement System Capability Analysis. Introd. to Stat. Qual. Control. Seventh Ed, John Wiley \& Sons Inc.; 2013, p. 365.

[38] Knapp W. Tolerance and uncertainty. Fifth Int. Conf. Laser Metrol. Mach. Tool, C. Robot Performance, LAMDAMAP, 2001, p. 357-66.

[39] Knapp W. Measurement uncertainty and machine tool testing. CIRP Ann Technol 2002;51:459-62.

[40] Tosello G, Hansen HN, Gasparin S. Applications of dimensional micro metrology to the product and process quality control in manufacturing of 
precision polymer micro components. CIRP Ann Technol 2009;58:467-72. 


\section{Figure Captions}

Fig. 1 Effect of tolerances on design and production

Fig. 2 Schematic of a multi-stage cold former with two forming operations: (a) before

forming, (b) after squeezing billets in forming inserts

Fig. 3 Stock material; Form: coil, Material: EN-AW 1050A, Temper H14 30

Fig. 4 Link between requirements and achieved tolerances for sheared billets

Fig. 5 Tools used in shearing process for volume production of billets

Fig. 6 Uncertainty range $( \pm \mathrm{U})$ reduces the conformity and nonconformity zones; (1)

conformity zone, (2) nonconformity zone, (3) measurement uncertainty

Fig. 7 Normality tests of data for length and weight using histograms and probability plots along with Ryan-Joiner test (P-value), (a) histogram of length (b) histogram of weight (c) probability plot of length (d) probability plot of weight 35

Fig. $8 \bar{x}$ and R charts (from Minitab) for (a) length (b) weight 36 


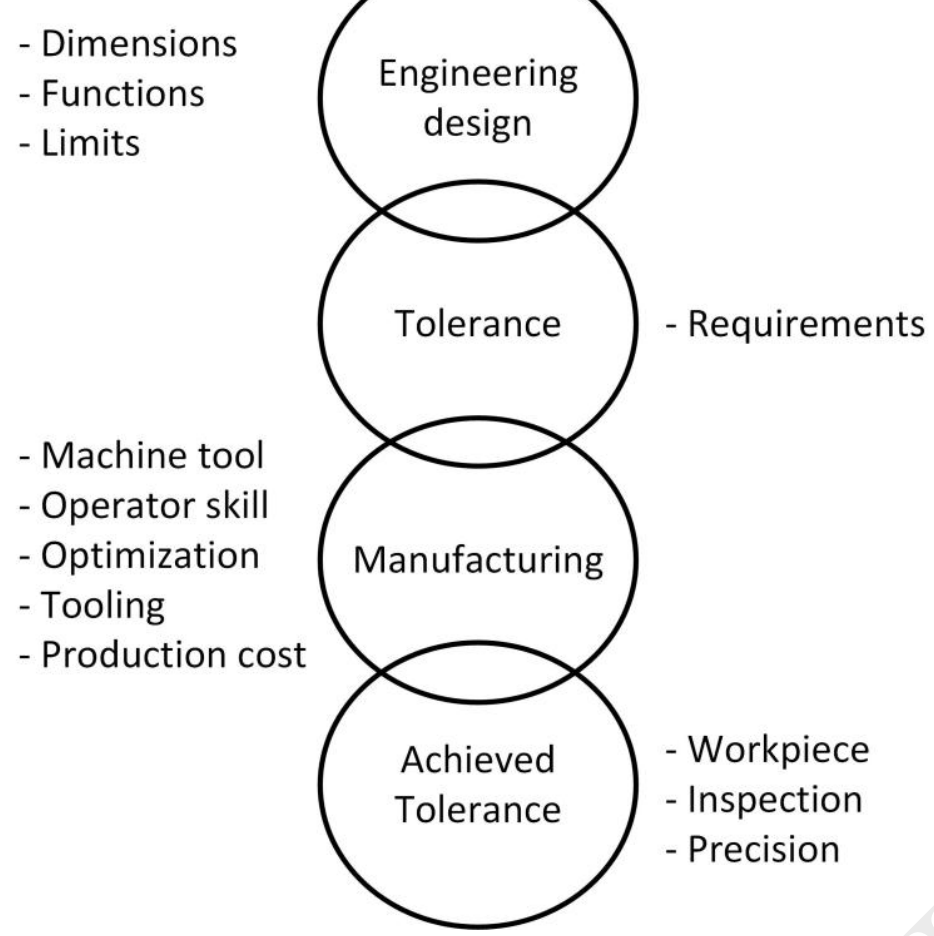

Fig. 1 Effect of tolerances on design and production 


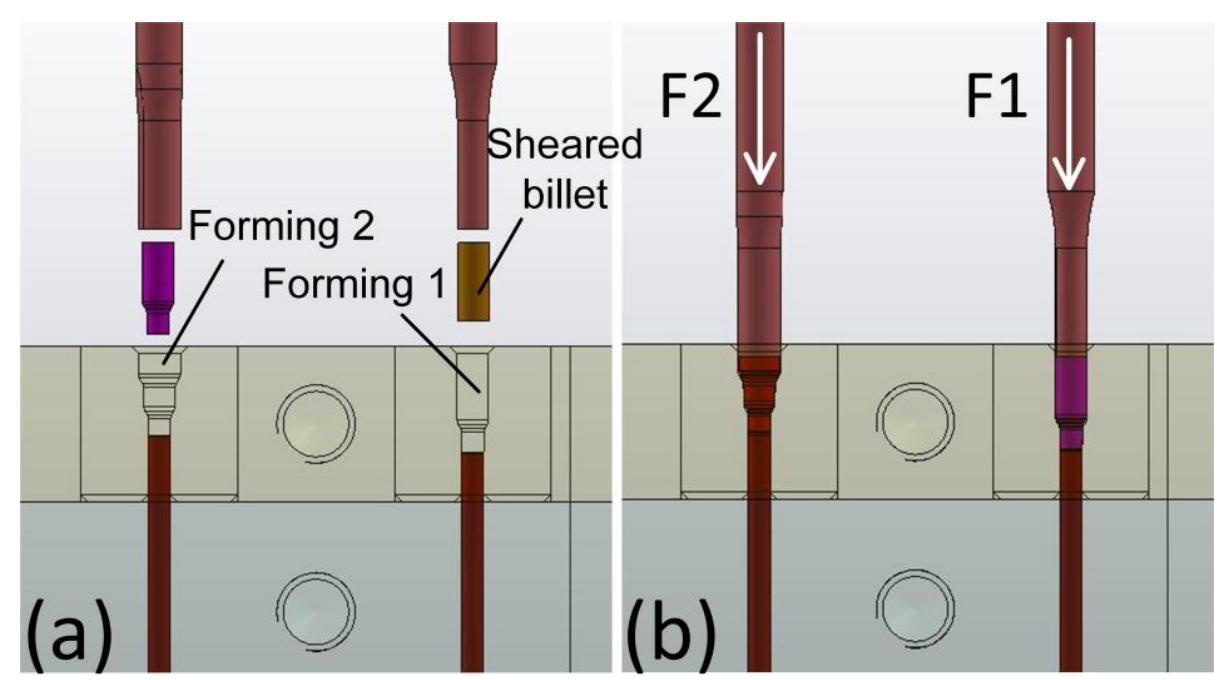

Fig. 2 Schematic of a multi-stage cold former with two forming operations: (a) before forming, (b) after squeezing billets in forming inserts 


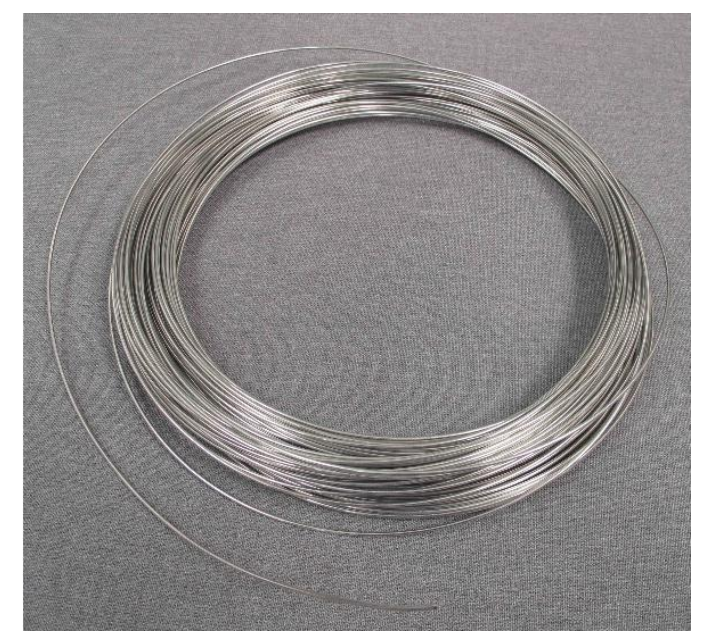

Fig. 3 Stock material; Form: coil, Material: EN-AW 1050A, Temper H14 


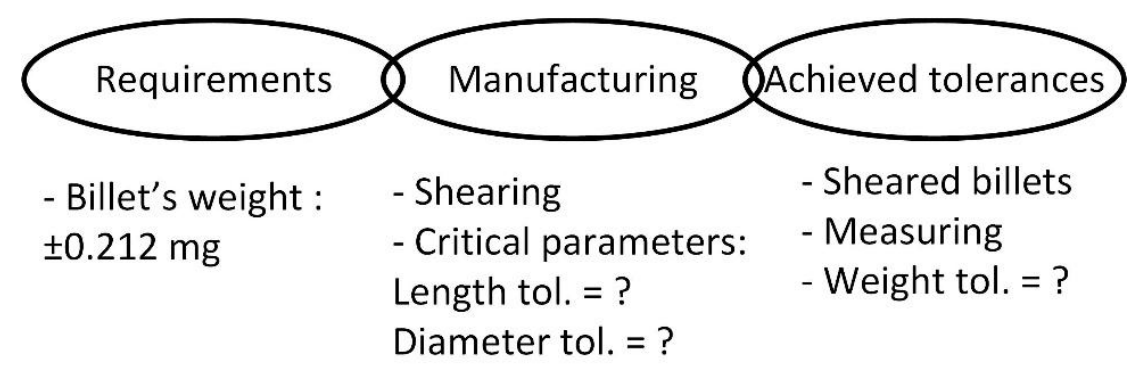

Fig. 4 Link between requirements and achieved tolerances for sheared billets 


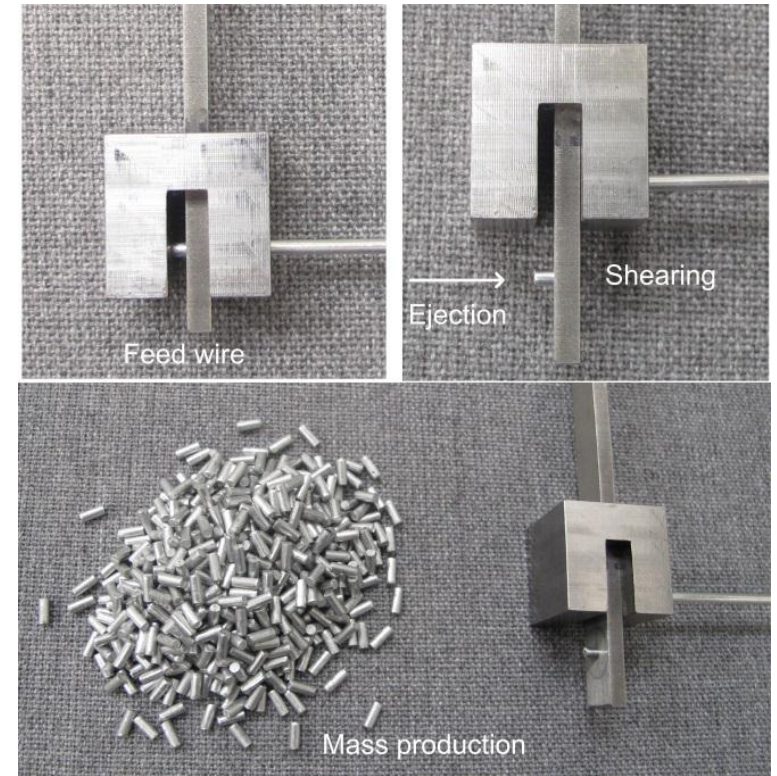

Fig. 5 Tools used in shearing process for volume production of billets 


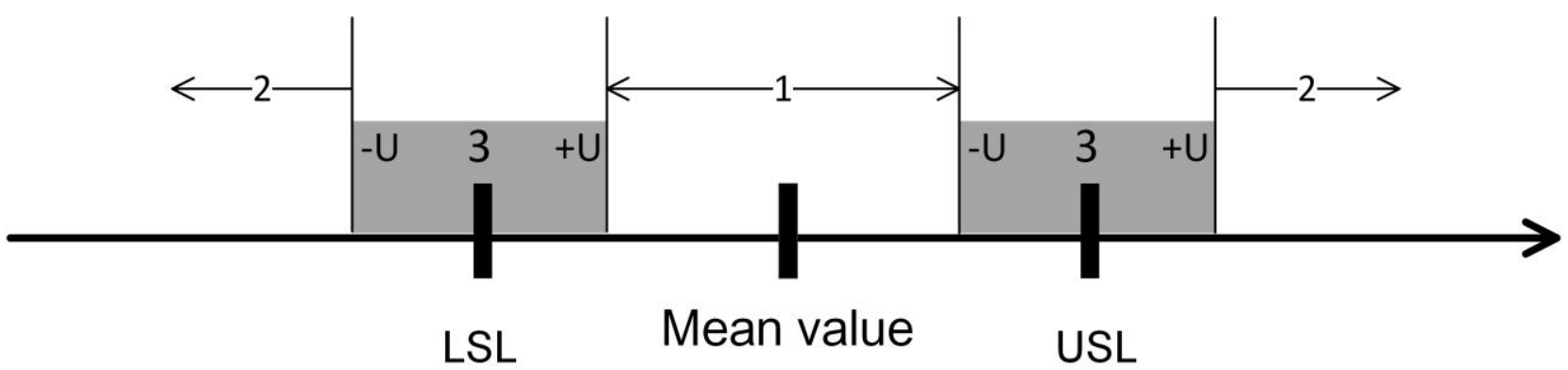

Fig. 6 Uncertainty range $( \pm U)$ reduces the conformity and nonconformity zones; (1) conformity zone, (2) nonconformity zone, (3) measurement uncertainty 


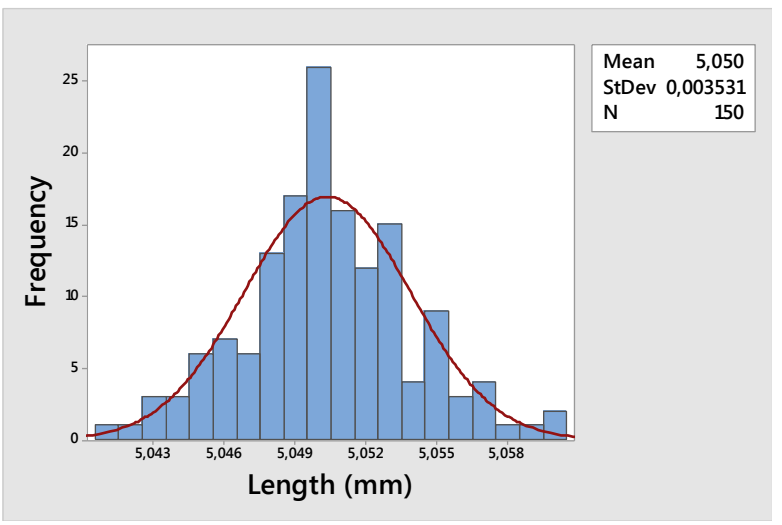

(a)

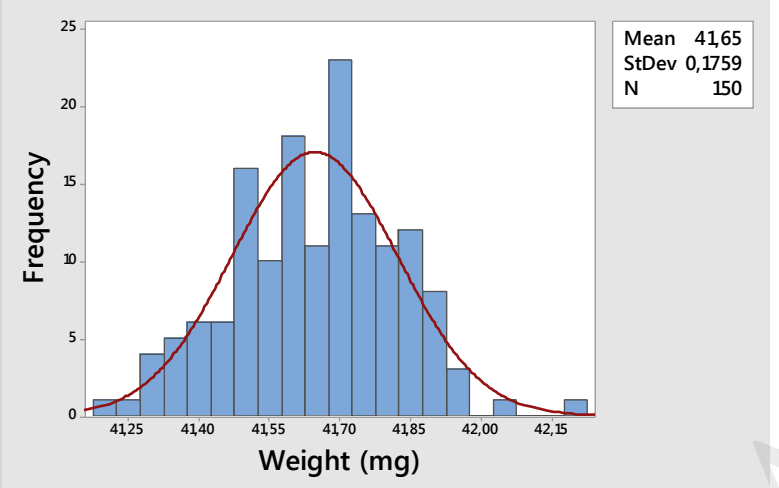

(b)

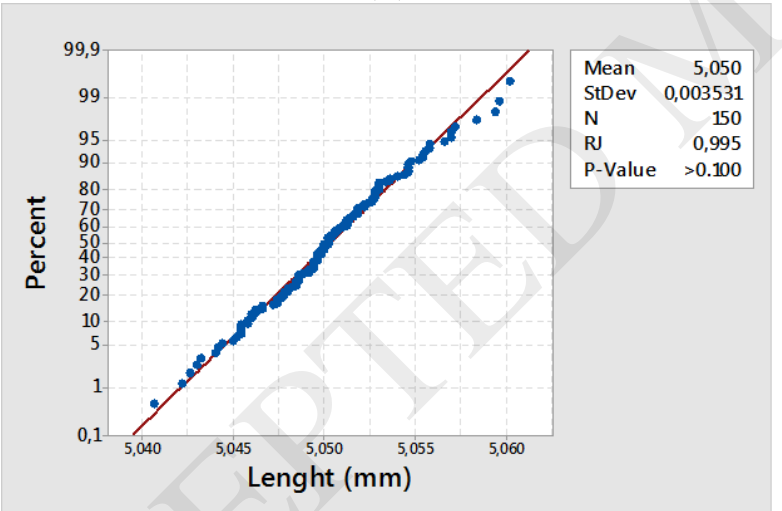

(c)

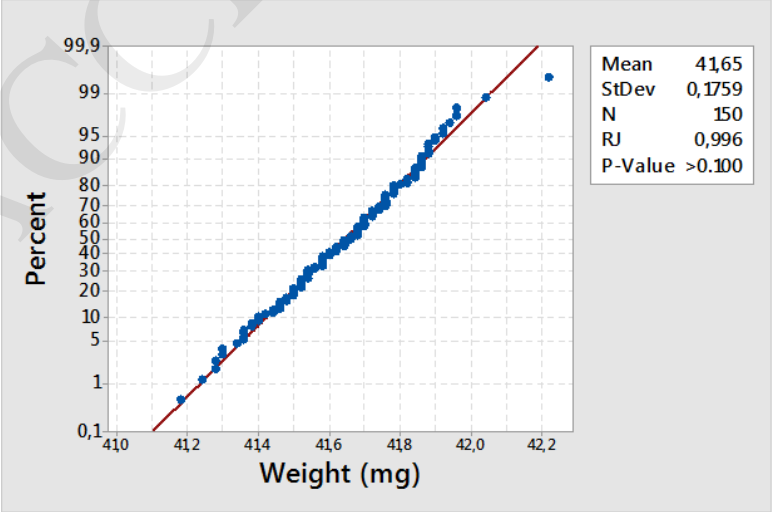

(d) 
Fig. 7 Normality tests of data for length and weight using histograms and probability plots along with Ryan-Joiner test (P-value), (a) histogram of length (b) histogram of weight (c) probability plot of length (d) probability plot of weight 


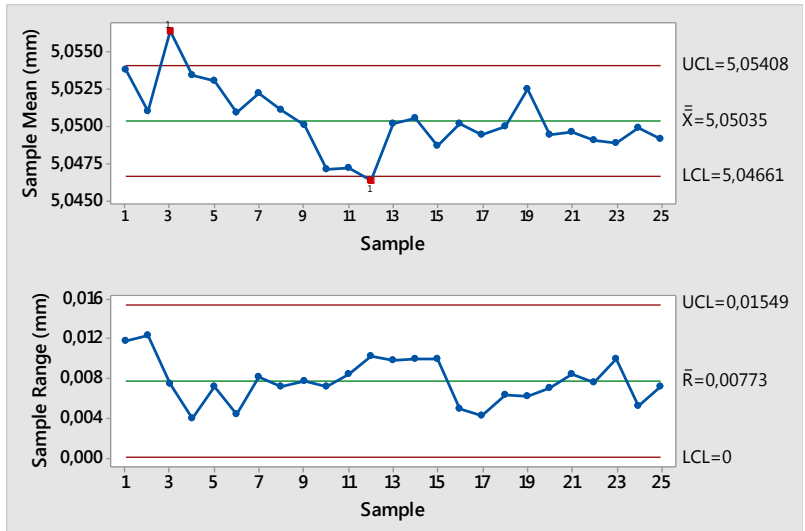

(a)

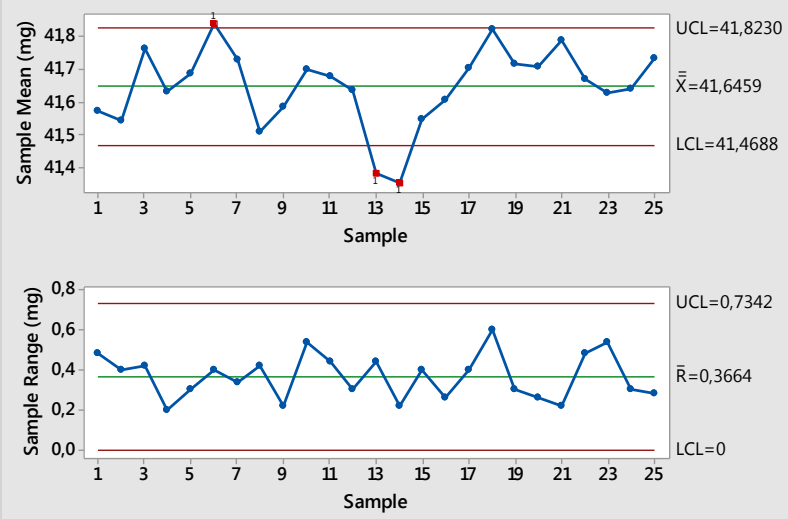

(b)

Fig. $8 \bar{x}$ and R charts (from Minitab) for (a) length (b) weight 


\section{Tables}

Table 1 Summary of symbols used in uncertainty calculations

\begin{tabular}{ll}
\hline Symbols & Description \\
\hline$x_{i}$ & Value for a given $x_{i}$ variable \\
$y=f\left(x_{i}\right)$ & Quantity to be determined, or measurand \\
$U$ & Expanded uncertainty \\
$P$ & Confidence level \\
$v$ & Degree of freedom \\
$k$ & Coverage factor \\
$s$ & standard deviation from sample measurements \\
$a$ & Standard uncertainty for Type B \\
$u^{2}\left(x_{i}\right)$ & Standard uncertainty squared for a given $x_{i}$ variable \\
$c_{i}=\partial y / \partial x_{i}$ & Partial derivative of $y$ with respect to $x_{i}$ \\
$u_{i}^{2}(y)$ & Squared standard uncertainty in y for a given $x_{i}$ variable \\
$u_{c}(y)$ & Combined standard uncertainty in $y$ \\
\hline
\end{tabular}

Table 2 Measurement uncertainty of micrometer using gauge block

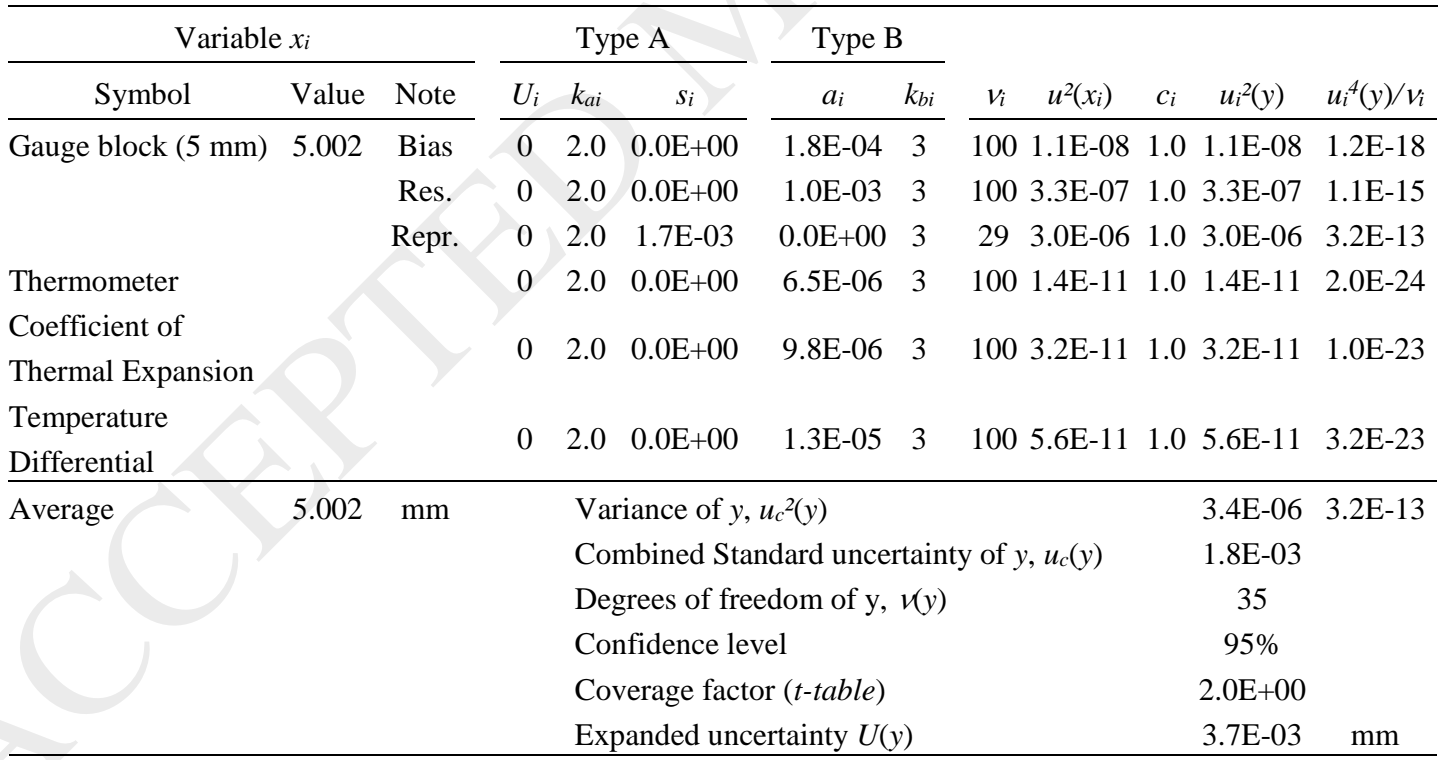


Table 3 Measurement uncertainty for billet's length

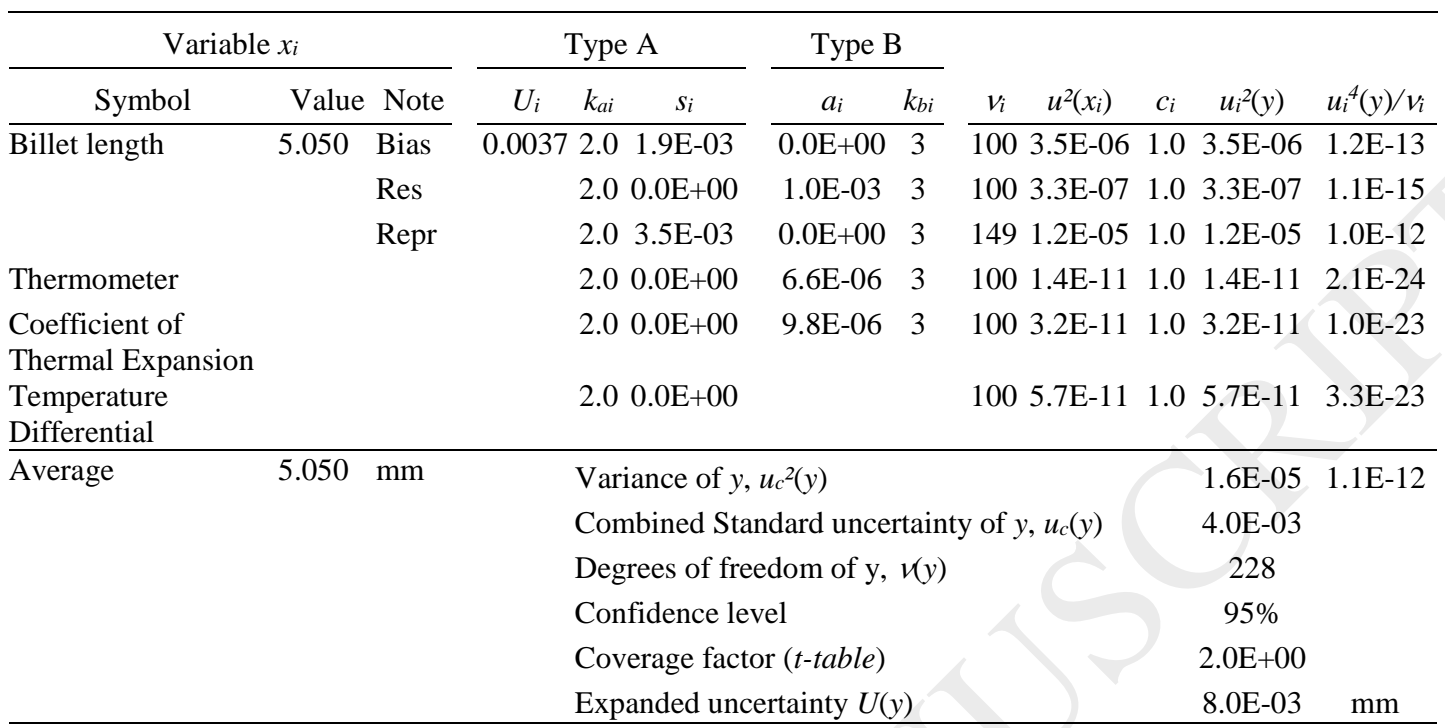

Table 4 Uncertainty calculation for weight of billets

\begin{tabular}{|c|c|c|c|c|c|c|c|c|c|c|c|}
\hline \multicolumn{3}{|c|}{ Variable $x_{i}$} & \multicolumn{2}{|c|}{ Type A } & \multicolumn{2}{|c|}{ Type B } & \multirow[b]{2}{*}{$v_{i}$} & \multirow[b]{2}{*}{$u^{2}\left(x_{i}\right)$} & \multirow[b]{2}{*}{$c_{i}$} & \multirow[b]{2}{*}{$u_{i^{2}(y)}$} & \multirow[b]{2}{*}{$u_{i}^{4}(y) / v_{i}$} \\
\hline Symbol & Value & Note & $U_{i} \quad k_{a i}$ & $s_{i}$ & $a_{i}$ & $k_{b i}$ & & & & & \\
\hline \multirow[t]{3}{*}{ Billet weight } & 41.646 & Bias & 2.0 & $0.0 \mathrm{E}+00$ & $1.0 \mathrm{E}-01$ & 3 & 100 & $3.3 \mathrm{E}-03$ & 1.0 & $3.3 \mathrm{E}-03$ & $1.1 \mathrm{E}-07$ \\
\hline & & Res. & 2.0 & $0.0 \mathrm{E}+00$ & $1.0 \mathrm{E}-01$ & 3 & 100 & $3.3 \mathrm{E}-03$ & 1.0 & 3.3E-03 & $1.1 \mathrm{E}-07$ \\
\hline & & Repr. & 2.0 & $1.8 \mathrm{E}-01$ & $0.0 \mathrm{E}+00$ & 3 & 149 & $3.1 \mathrm{E}-02$ & 1.0 & $3.1 \mathrm{E}-02$ & $6.4 \mathrm{E}-06$ \\
\hline \multirow[t]{6}{*}{ Average } & 5.002 & $\mathrm{~mm}$ & \multicolumn{4}{|c|}{ Variance of $y, u_{c}^{2}(y)$} & & & & $3.8 \mathrm{E}-02$ & $6.6 \mathrm{E}-06$ \\
\hline & & & \multicolumn{6}{|c|}{ Combined Standard uncertainty of $y, u_{c}(y)$} & & $1.9 \mathrm{E}-01$ & \\
\hline & & & \multicolumn{4}{|c|}{ Degrees of freedom of $\mathrm{y}, v(y)$} & & & & 212 & \\
\hline & & & \multicolumn{4}{|c|}{ Confidence level } & & & & $95 \%$ & \\
\hline & & & \multicolumn{4}{|c|}{ Coverage factor $(t$-table $)$} & & & & $2.0 \mathrm{E}+00$ & \\
\hline & & & \multicolumn{4}{|c|}{ Expanded uncertainty $U(y)$} & & & & 3.9E-01 & $\mathrm{mg}$ \\
\hline
\end{tabular}

Table 5 Uncertainty calculation of the diameter using functional relationship

\begin{tabular}{|c|c|c|c|c|c|c|c|c|c|c|c|c|}
\hline \multicolumn{3}{|c|}{ Variable $x_{i}$} & \multicolumn{3}{|c|}{ Type A } & \multicolumn{2}{|c|}{ Type B } & \multirow[b]{2}{*}{$v_{i}$} & \multirow[b]{2}{*}{$u^{2}\left(x_{i}\right)$} & \multirow[b]{2}{*}{$c_{i}$} & \multirow[b]{2}{*}{$u_{i}^{2}(y)$} & \multirow[b]{2}{*}{$u_{i}^{4}(y) / v_{i}$} \\
\hline Symbol & Value & Note & $U_{i}$ & $k_{a i}$ & $s_{i}$ & $a_{i}$ & $k_{b i}$ & & & & & \\
\hline $\begin{array}{l}\text { Height } \\
(\mathrm{mm})\end{array}$ & 5.050 & & 8.0E-03 & 2.04 & 0E-03 & $0.0 \mathrm{E}+00$ & 3 & 149 & $1.6 \mathrm{E}-05$ & $-2.0 \mathrm{E}-01$ & $6.1 \mathrm{E}-07$ & $2.5 \mathrm{E}-15$ \\
\hline Mass (g) & 0.4165 & & $3.9 \mathrm{E}-04$ & 2.02 & OE-04 & $1.0 \mathrm{E}-04$ & 3 & 149 & 3.9E-08 & $2.4 \mathrm{E}+01$ & $2.2 \mathrm{E}-05$ & $3.1 \mathrm{E}-12$ \\
\hline $\begin{array}{l}\text { Density } \\
\left(\mathrm{g} / \mathrm{mm}^{3}\right)\end{array}$ & 0.0027 & Table & & 2.00 & $\mathrm{E}+00$ & $1.4 \mathrm{E}-02$ & 3 & 100 & 0.0 & $-3.7 \mathrm{E}+02$ & $0.0 \mathrm{E}+00$ & $0.0 \mathrm{E}+00$ \\
\hline \multirow[t]{2}{*}{ Average } & 5.050 & $\mathrm{~mm}$ & & \multicolumn{4}{|c|}{ Variance of $y, u_{c}^{2}(y)$} & & & & $2.2 \mathrm{E}-05$ & $3.1 \mathrm{E}-12$ \\
\hline & & & & \multicolumn{6}{|c|}{ Combined Standard uncertainty of $y, u_{c}(y)$} & & 4.7E-03 & \\
\hline
\end{tabular}


Table 6 Statistics of length, weight and diameter of sheared billets

\begin{tabular}{lccl}
\hline Parameter & Mean & STDV & Uncertainty \\
\hline Length $(\mathrm{mm})$ & 5.050 & 0.0035 & 0.008 \\
Weight $(\mathrm{mg})$ & 41.65 & 0.1759 & 0.39 \\
Diameter $(\mathrm{mm})$ & 1.971 & 0.0042 & 0.0093 \\
\hline
\end{tabular}

Table 7 Tolerance analysis using process capability ratio, and uncertainty-to-tolerance ratio for length

\begin{tabular}{lllll}
\hline$C_{p}$ & $\begin{array}{l}\text { Defective } \\
\text { parts }(\mathrm{ppm})\end{array}$ & Tolerance & $\begin{array}{l}\text { Length } \\
(\mathrm{mm})\end{array}$ & $\begin{array}{l}U / T \\
\text { ratio } \\
\text { (Length) }\end{array}$ \\
\hline 0.33 & 317311 & $\pm 1 \sigma$ & $\pm 3.5 \mathrm{E}-3$ & - \\
0.67 & 45500 & $\pm 2 \sigma$ & $\pm 7.1 \mathrm{E}-3$ & - \\
1 & 2700 & $\pm 3 \sigma$ & $\pm 10.6 \mathrm{E}-3$ & $75 \%$ \\
1.33 & 63 & $\pm 4 \sigma$ & $\pm 14.1 \mathrm{E}-3$ & $57 \%$ \\
1.5 & 7 & $\pm 4.5 \sigma$ & $\pm 15.9 \mathrm{E}-3$ & $50.3 \%$ \\
2 & 0.002 & $\pm 6 \sigma$ & $\pm 21.2 \mathrm{E}-3$ & $38 \%$ \\
\hline
\end{tabular}

Table 8 Tolerance analysis using process capability ratio, and uncertainty-to-tolerance ratio for diameter

\begin{tabular}{lllll}
\hline$C_{p}$ & $\begin{array}{l}\text { Defective } \\
\text { parts }(\mathrm{ppm})\end{array}$ & Tolerance & $\begin{array}{l}\text { Diameter } \\
(\mathrm{mm})\end{array}$ & $\begin{array}{l}U / T \text { ratio } \\
\text { (Diameter) }\end{array}$ \\
\hline 0.33 & 317311 & $\pm 1 \sigma$ & $\pm 4.2 \mathrm{E}-3$ & - \\
0.67 & 45500 & $\pm 2 \sigma$ & $\pm 8.4 \mathrm{E}-3$ & - \\
1 & 2700 & $\pm 3 \sigma$ & $\pm 12.7 \mathrm{E}-3$ & $73 \%$ \\
1.33 & 63 & $\pm 4 \sigma$ & $\pm 16.9 \mathrm{E}-3$ & $55 \%$ \\
1.5 & 7 & $\pm 4.5 \sigma$ & $\pm 19.0 \mathrm{E}-3$ & $49.0 \%$ \\
2 & 0.002 & $\pm 6 \sigma$ & $\pm 25.3 \mathrm{E}-3$ & $37 \%$ \\
\hline
\end{tabular}


Table 9 Comparing weight tolerance using process capability ratio, Worst-case (WC) and root-sum-squared (RSS) methods

\begin{tabular}{llll}
\hline $\begin{array}{l}\text { Proposed } \\
\text { method }(\mathrm{mg})\end{array}$ & $\begin{array}{l}\text { U/T ratio } \\
\text { (Weight) }\end{array}$ & $\begin{array}{l}\text { WC } \\
(\mathrm{mg})\end{array}$ & $\begin{array}{l}\text { RSS } \\
(\mathrm{mg})\end{array}$ \\
\hline \pm 0.1759 & - & 0.2074 & 0.1807 \\
\pm 0.3518 & - & 0.4148 & 0.3613 \\
\pm 0.5277 & $74 \%$ & 0.6222 & 0.5420 \\
\pm 0.7036 & $55 \%$ & 0.8297 & 0.7226 \\
\pm 0.7916 & $49.3 \%$ & 0.9334 & 0.8130 \\
\pm 1.0554 & $37 \%$ & 1.2445 & 1.0839 \\
\hline
\end{tabular}

